OPEN ACCESS

Edited by:

Sapna Patel,

University of Texas MD Anderson

Cancer Center, United States

Reviewed by:

Andrzej T. Slominski,

University of Alabama at Birmingham,

United States

Simone Ribero,

University of Turin, Italy

*Correspondence:

Jiuzuo Huang

hiz1983@126.com

Xiao Long

pumclongxiao@126.com

${ }^{\dagger}$ These authors have contributed equally to this work and share first authorship

Specialty section: This article was submitted to Skin Cancer.

a section of the journal

Frontiers in Oncology

Received: 18 November 2021 Accepted: 10 January 2022

Published: 27 January 2022

Citation:

Huang H, Fu Z, Ji J, Huang J and Long $X$ (2022) Predictive Values of Pathological and Clinical Risk Factors for Positivity of Sentinel Lymph Node Biopsy in Thin Melanoma: $A$ Systematic Review and Meta-Analysis.

Front. Oncol. 12:817510.

doi: 10.3389/fonc.2022.817510

\section{Predictive Values of Pathological and Clinical Risk Factors for Positivity of Sentinel Lymph Node Biopsy in Thin Melanoma: A Systematic Review and Meta-Analysis}

\author{
Hanzi Huang ${ }^{\dagger}$, Ziyao $\mathrm{Fu}^{\dagger}$, Jiang Ji, Jiuzuo Huang ${ }^{*}$ and Xiao Long ${ }^{*}$ \\ Department of Plastic Surgery, Peking Union Medical College Hospital (PUMCH), Chinese Academy of Medical Sciences and \\ Peking Union Medical College, Beijing, China
}

Background: The indications for sentinel lymph node biopsy (SLNB) for thin melanoma are still unclear. This meta-analysis aims to determine the positive rate of SLNB in thin melanoma and to summarize the predictive value of different high-risk features for positive results of SLNB.

Methods: Four databases were searched for literature on SLNB performed in patients with thin melanoma published between January 2000 and December 2020. The overall positive rate and positive rate of each high-risk feature were calculated and obtained with 95\% confidence intervals (Cls). Both unadjusted odds ratios (ORs) and adjusted ORs (AORs) of high-risk features were analyzed. Pooled effects were estimated using randomeffects model meta-analyses.

Results: Sixty-six studies reporting 38,844 patients with thin melanoma who underwent SLNB met the inclusion criteria. The pooled positive rate of SLNB was 5.1\% [95\% confidence interval $(\mathrm{Cl})$ 4.9\%-5.3\%]. Features significantly predicted a positive result of SLNB were thickness $\geq 0.8 \mathrm{~mm}$ [AOR $1.94(95 \% \mathrm{Cl} 1.28-2.95)$; positive rate $7.0 \%(95 \% \mathrm{Cl} 6.0-8.0 \%)]$; ulceration [AOR 3.09 (95\% Cl 1.75-5.44); positive rate 4.2\% (95\% Cl 1.8-7.2\%)]; mitosis rate $>0 / \mathrm{mm} 2$ [AOR 1.63 (95\% Cl 1.13-2.36); positive rate 7.7\% (95\% Cl 6.3-9.1\%)]; microsatellites [OR $3.8(95 \% \mathrm{Cl} 1.38-10.47)$; positive rate $16.6 \%(95 \% \mathrm{Cl} 2.4-36.6 \%)]$; and vertical growth phase [OR $2.76(95 \% \mathrm{Cl} 1.72-4.43)$; positive rate $8.1 \%(95 \% \mathrm{Cl} 6.3-10.1 \%)]$.

Conclusions: The overall positive rate of SLNB in thin melanoma was 5.1\%. The strongest predictor for SLN positivity identified was microsatellites on unadjusted analysis and ulceration on adjusted analysis. Breslow thickness $\geq 0.8 \mathrm{~mm}$ and mitosis rate $>0 / \mathrm{mm}^{2}$ both predict SLN positivity in adjusted analysis and increase the positive rate to $7.0 \%$ and $7.7 \%$. We suggest patients with thin melanoma with the above high-risk features should be considered for giving an SLNB.

Keywords: thin melanoma, sentinel lymph node biopsy, positive rate, ulceration, microsatellites, Breslow thickness, mitosis rate 


\section{INTRODUCTION}

The incidence of melanoma has been increasing rapidly over the past few decades, with 100,350 new cases diagnosed in America in 2020 , most of which are thin melanoma (T1, $\leq 1.0 \mathrm{~mm})(1)$. Although thin melanomas have a relatively good prognosis with a 10 -year survival rate of more than $95 \%$, the absolute number of deaths is notable because of the volume of the disease (2).

To identify melanoma with a poor prognosis and provide more precise treatment, sentinel lymph node biopsy (SLNB) was proposed by surgeons. SLNB is generally considered appropriate for melanoma of T2 or thicker, but the indications for sentinel lymph node biopsy for thin melanoma are still controversial. The positive rate of SLNB for thin melanoma reported by previous studies is approximately $5 \%(3-5)$. In addition, SLNB carries a false negative rate of $12.5 \%$ (6) and several unwanted complications, including infection (2.9\%), seroma (5.1\%), hematoma $(0.5 \%)$, lymphoedema $(1.3 \%)$, and nerve injury (0.3\%) (7).

It is critical to recognize thin melanoma with high-risk pathologic features and to reduce unnecessary invasive manipulation. The mainstream view is that SLNB should be performed in thin melanomas only if high-risk features are indicating SLNB positivity and worse prognosis, such as Breslow thickness $>0.75 \mathrm{~mm}$, ulceration, Clark level IV/V, and/ or high mitotic rate $(4,8)$. The American Joint Committee on Cancer (AJCC) $8^{\text {th }}$ edition of the guidelines for melanoma published in 2018 is currently in wide clinical use. T1 melanoma was reclassified into T1a $(<0.8 \mathrm{~mm})$ and T1b $(0.8-$ $1.0 \mathrm{~mm}$, or any ulceration $\leq 1 \mathrm{~mm}$ ) (9). According to the National Comprehensive Cancer Network (NCCN) guidelines of cutaneous melanoma, SLNB is recommended for T1b melanoma or T1a lesions with mitosis rate $\geq 2 / \mathrm{mm}^{2}$, lymphovascular invasion, or other combination of risk factors (10). In the European consensus-based interdisciplinary guideline for melanoma, however, SLNB is recommended only for melanoma $\geq 0.8 \mathrm{~mm}$ with ulceration, mitosis rate $\geq 1 / \mathrm{mm}^{2}$, microsatellites, or other risk factors (11).

The purpose of this meta-analysis was to determine the positive rate of SLNB in thin melanoma and to summarize the predictive value of different clinical and high-risk pathological features for positive results of SLNB.

\section{METHODS}

This meta-analysis followed and adhered to the Preferred Reporting Items for Systematic Reviews and Meta-Analyses guidelines.

\section{Search Strategy}

We searched literature published between January 2000 and December 2020 from the PubMed, Embase, Web of Science, and Cochrane Library databases. English articles with "melanoma", or "melanomas", and "sentinel lymph node biopsy", or "SLNB", or "SNB" were screened. Through reviewing the titles and abstracts of the retrieved literature, we selected potentially eligible studies preliminarily and further reviewed the full texts to determine whether they met the inclusion criteria. Two authors (HHZ \& FZY) reviewed all literature obtained and examined whether each of them met the inclusion criteria.

To reduce potential bias due to the small sample size, we set the included criteria, which require a sample size for each study to be larger than 50. The inclusion criteria were as follows: including patients with a pathologic diagnosis of thin melanoma (Breslow thickness $\leq 1.0 \mathrm{~mm}$ ) in the study; performing SLNB for $>50$ patients with thin melanoma, and reporting an SLN positivity rate. Reference lists of included articles and related literature were manually searched to complete the deficiency of computer search.

When multiple studies reported overlapping or duplicate patient sources, only the most recent and comprehensive study was included. Studies that did not report negative sentinel lymph nodes (SLNs) or included a single isolated high-risk pathologic feature were excluded. Case reports, literature reviews, commentaries, editorials, letters, and conference abstracts were also excluded.

\section{Data Extraction and Quality Assessment}

The following data were extracted from studies: 1) study information, including first author and publication year; 2) patient characteristics, including the number of SLNBs performed in patients with thin melanoma, clinical feature (primary tumor location), high-risk pathologic features [Breslow thickness, mitosis rate, Clark Level, ulceration, regression, microsatellites, vertical growth phase, tumorinfiltrating lymphocytes (TIL) and lymphovascular invasion (LVI)]; 3) outcomes, including the number of positive SLNs found in patients with thin melanoma and number of patients with thin melanoma reporting both positive SLN and high-risk features; 4) adjusted odds ratio (OR) for each high-risk pathologic feature if available.

Two authors (HHZ \& FZY) used the Newcastle Ottawa Scale (NOS) to assess the risk of bias in the included studies. The NOS evaluates literature quality in three aspects: selection, comparability, and outcomes. The maximum score was 9 , and a score greater than 6 is considered to indicate a low risk of bias.

\section{Statistical Analysis}

The primary outcome was the positive rate of SLNB in thin melanoma (Breslow thickness $\leq 1.0 \mathrm{~mm}$ ), and the pooled effect was calculated and obtained with $95 \%$ confidence intervals (CIs). Forest plots were constructed to visually represent the results. The secondary outcomes were the predictive value of high-risk pathologic and clinical features for positive results of SLNB. Unadjusted ORs and adjusted ORs were pooled and analyzed using a random-effects model. Additionally, pooled positive rates of SLNB in patients with each pathologic feature were calculated. Heterogeneity among studies was calculated by the $\mathrm{I}^{2}$ measure of inconsistency, and an $\mathrm{I}^{2}>50 \%$ indicated significant heterogeneity. The presence of publication bias was investigated visually using a funnel plot. Meta-analysis was performed by Stata/MP software (version 16.0 for Windows, StataCorp LLC, College Station, TX77845, USA). 


\section{RESULTS}

\section{Characteristics of Included Studies}

The process of study selection is described in Figure 1. A total of 6424 articles were obtained through retrieval, and 66 of them met the inclusion criteria. All of the included studies were retrospective, reporting 38,844 patients with thin melanoma who underwent SLNB (Table 1) $(8,12-76)$. The number of included patients in each study ranged from 51 to 9186 , with a median of 205. A total of 2117 (5.45\%) positive SLN cases were found among all patients. Thirty-eight of the 66 included studies reported at least one high-risk pathologic feature that may be associated with SLN positivity. A median NOS score of 7 (range from 6 to 8 ) indicated that the risk of bias of the included studies was small. No study was excluded based on the NOS quality assessment. No significant publication bias among the included studies was found by funnel plot (Figure 2).

\section{Outcomes}

For the primary outcome, a pooled positive rate of SLNB was estimated by applying the random effect model, calculated as $5.1 \%$ (95\% CI, $4.5 \%$ to 5.6\%, Figure 3). Significant heterogeneity between studies was detected $\left(\mathrm{I}^{2}=73.6 \%, \mathrm{p}<0.001\right)$. The unadjusted ORs and pooled positive rate of each high-risk pathologic and clinical feature for SLN positivity is shown in Table 2. Breslow thickness $\geq 0.8 \mathrm{~mm}$, presence of ulceration, mitosis rate $>0 / \mathrm{mm}^{2}$, Clark level IV $/ \mathrm{V}$, and vertical growth phase showed a significant association with SLN positivity in unadjusted analysis. All of the above pathologic features showed a pooled positive rate higher than $5.1 \%$ except for the presence of ulceration. Notably, we found the presence of
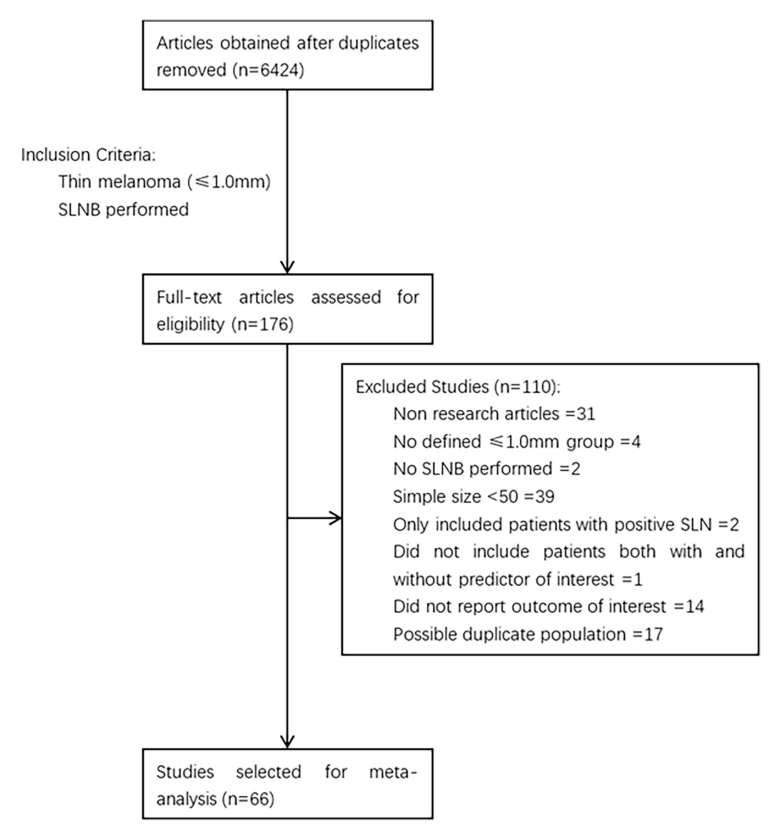

FIGURE 1 | Process study selection. microsatellites to be most strongly associated with SLN positivity, with an unadjusted OR of 3.8 (95\% CI, 1.38 to 10.47) and a pooled positive rate of $16.6 \%$ (95\% CI, $2.4 \%$ to $36.6 \%)$.

The adjusted ORs of pathologic features are shown in Table 3. There were only 11 studies that had adjusted OR data that could be analyzed. Pathologic features that were available for adjusted analysis were limited as the presence of ulceration, Breslow thickness $\geq 0.8 \mathrm{~mm}$, mitosis rate $>0 / \mathrm{mm}^{2}$, Clark level IV/V, and the presence of regression. Breslow thickness $\geq 0.8 \mathrm{~mm}$, presence of ulceration, mitosis rate $>0$ / $\mathrm{mm}^{2}$ showed a significant association with SLN positivity in the adjusted analysis, while Clark level IV/V did not show a significant correlation with SLN positivity. Among these, the presence of ulceration was the strongest predictor of positive SLNB results in the adjusted analysis, with an adjusted OR of 2.75 (95\%CI, 1.65 to 4.60 ).

The associations between SLN positivity and the primary tumor location, the absence or presence of regression, LVI, or TIL were found with insufficient evidence.

\section{DISCUSSION}

It is critical to identify thin melanoma with a worse prognosis so that patients can be able to receive precise therapies. Researchers around the world have been interested in investigating an effective prediction for the prognosis of thin melanoma. Several pieces of research have been published in the past few years. This study is the most recent and most comprehensive meta-analysis to date. Compared with the previous meta-analysis, this study included 19 newly published research articles since 2015, reporting 26,308 patients in total who had a diagnosis of thin melanoma and underwent SLNB.

The pooled estimated positive rate of SLNB in thin melanoma in this study was $5.1 \%$, with a $95 \%$ CI of $4.5 \%$ to $5.6 \%$. This result is similar to those found in preexisting meta-analyses, which reported pooled positive rates of $5.6 \%, 4.5 \%$, and $5.1 \%(3-5)$, but we got narrower confidence intervals. A $5 \%$ risk threshold is often used for surgeons suggesting to perform SLNB for a patient $(37,77)$. Generally, SLNB is offered to patients with primary melanoma with Breslow thickness $\geq 0.8 \mathrm{~mm}$ with additional risk factors. But different risk factors are recommended in different guidelines $(10,11)$. Therefore we analyzed the predictive value of multiple pathological and clinical features for the positive SLN.

In this study, we not only updated the predictive value of pathologic features explored in the previous meta-analysis but also paid attention to primary tumor location, which was reported to be correlated with a positive SLN (34). We yielded some different results. Ulceration, Clark level, and Breslow thickness were commonly recorded features in patients, reporting in $37.9 \%, 36.4 \%$, and $34.8 \%$ of included studies, respectively. In the unadjusted analysis in our study, we recognized the same significant predictors as the previous meta-analysis and the primary tumor location was not significantly related to SLN positivity. And in the adjusted analysis in our study, however, the presence of ulceration was 
TABLE 1 | Characteristic of the 66 included studies.

\begin{tabular}{|c|c|c|c|c|c|}
\hline Study & Year & $\begin{array}{l}\text { Total No. of thin melanoma } \\
\text { patients undergoing SLNB }\end{array}$ & $\begin{array}{l}\text { Total No. of thin melanoma patients } \\
\text { with positive SLN (\%) }\end{array}$ & High-risk features reported & $\begin{array}{l}\text { Risk of bias Score } \\
\text { (NOS) (Max=9) }\end{array}$ \\
\hline Theile et al. (12) & 2020 & 240 & $14(5.8 \%)$ & Thickness, ulceration & 6 \\
\hline $\begin{array}{l}\text { Skochdopole } \\
\text { et al. (13) }\end{array}$ & 2020 & 4332 & $229(5.3 \%)$ & Thickness & 6 \\
\hline Kocsis et al. (14) & 2020 & 78 & $9(11.5 \%)$ & Ulceration, regression & 7 \\
\hline Hu et al. (15) & 2020 & 238 & $19(8.0 \%)$ & Nil & 7 \\
\hline $\begin{array}{l}\text { Antonialli et al. } \\
\text { (16) }\end{array}$ & 2020 & 399 & $27(6.8 \%)$ & Nil & 7 \\
\hline $\begin{array}{l}\text { Tejera- } \\
\text { Vaquerizo et al. } \\
\text { (17) }\end{array}$ & 2019 & 1083 & $73(6.7 \%)$ & Nil & 8 \\
\hline $\begin{array}{l}\text { Santos et al. } \\
\text { (18) }\end{array}$ & 2019 & 137 & $10(7.3 \%)$ & $\begin{array}{l}\text { Thickness, ulceration, MR, TIL, } \\
\text { regression, CL, microsatellites }\end{array}$ & 8 \\
\hline $\begin{array}{l}\text { Piazzalunga } \\
\text { et al. (19) }\end{array}$ & 2019 & 1272 & $76(6.0 \%)$ & Thickness, ulceration, MR, CL & 7 \\
\hline Conic et al. (8) & 2019 & 9186 & 457 (5.0\%) & $\begin{array}{l}\text { thickness, ulceration, MR, regression, } \\
\mathrm{CL}\end{array}$ & 8 \\
\hline Verver et al. (20) & 2018 & 1607 & $115(7.2 \%)$ & Nil & 7 \\
\hline Stiegel et al. (21) & 2018 & 326 & $25(7.7 \%)$ & Nil & 8 \\
\hline $\begin{array}{l}\text { Nguyen et al. } \\
(22)\end{array}$ & 2018 & 142 & 7 (4.9\%) & Nil & 6 \\
\hline $\begin{array}{l}\text { Isaksson et al. } \\
\text { (23) }\end{array}$ & 2018 & 1038 & $49(4.7 \%)$ & Thickness, ulceration, MR & 6 \\
\hline $\begin{array}{l}\text { Herbert et al. } \\
(24)\end{array}$ & 2018 & 1129 & $49(4.3 \%)$ & thickness & 7 \\
\hline $\begin{array}{l}\text { Tejera- } \\
\text { Vaquerizo et al. } \\
\text { (25) }\end{array}$ & 2017 & 203 & $14(6.9 \%)$ & MR, regression, microsatellites & 7 \\
\hline Joyce et al. (26) & 2017 & 65 & $1(1.5 \%)$ & Thickness, ulceration & 8 \\
\hline Wat et al. (27) & 2016 & 171 & $15(8.8 \%)$ & $\mathrm{MR}$ & 7 \\
\hline $\begin{array}{l}\text { Rubinstein et al. } \\
\text { (28) }\end{array}$ & 2016 & 252 & $6(2.4 \%)$ & Nil & 8 \\
\hline $\begin{array}{l}\text { Hieken et al. } \\
\text { (29) }\end{array}$ & 2015 & 4410 & $283(6.4 \%)$ & Nil & 7 \\
\hline Voit et al. (30) & 2014 & 288 & $15(5.2 \%)$ & Nil & 7 \\
\hline $\begin{array}{l}\text { Mitteldorf et al. } \\
\text { (31) }\end{array}$ & 2014 & 207 & $38(18.4 \%)$ & $\begin{array}{l}\text { Thickness, ulceration, MR, } \\
\text { regression, } \mathrm{CL}\end{array}$ & 7.5 \\
\hline $\begin{array}{l}\text { Bartlett et al. } \\
\text { (32) }\end{array}$ & 2014 & 781 & $29(3.7 \%)$ & $\begin{array}{l}\text { Thickness, ulceration, MR, TIL, } \\
\text { regression, CL, LVI, microsatellites }\end{array}$ & 6.5 \\
\hline Balch et al. (33) & 2014 & 1213 & $73(6.0 \%)$ & Nil & 6 \\
\hline Venna et al. (34) & 2013 & 484 & $34(7.0 \%)$ & $\begin{array}{l}\text { Thickness, ulceration, MR, TIL, CL, } \\
\text { LVI }\end{array}$ & 6 \\
\hline $\begin{array}{l}\text { van den Broek } \\
\text { et al. (35) }\end{array}$ & 2013 & 61 & $0(0.0 \%)$ & Nil & 6 \\
\hline $\begin{array}{l}\text { Mozzillo et al. } \\
\text { (36) }\end{array}$ & 2013 & 492 & $24(4.9 \%)$ & Ulceration, MR & 8 \\
\hline Han et al. (37) & 2013 & 1250 & $65(5.2 \%)$ & $\begin{array}{l}\text { Thickness, ulceration, MR, TIL, } \\
\text { regression, CL, LVI, VGP }\end{array}$ & 7.5 \\
\hline $\begin{array}{l}\text { Cooper et al. } \\
\text { (38) }\end{array}$ & 2013 & 189 & $3(1.6 \%)$ & Ulceration, MR, CL & 7 \\
\hline Chu et al. (39) & 2013 & 106 & $3(2.8 \%)$ & Ulceration, MR, CL & 8 \\
\hline Ponti et al. (40) & 2012 & 286 & $3(1.0 \%)$ & Nil & 6 \\
\hline Murali et al. (41) & 2012 & 432 & $29(6.7 \%)$ & $\begin{array}{l}\text { Thickness, ulceration, MR, CL, LVI, } \\
\text { microsatellites }\end{array}$ & 7 \\
\hline $\begin{array}{l}\text { Koshenkov et al. } \\
\text { (42) }\end{array}$ & 2012 & 72 & $6(8.3 \%)$ & Ulceration, CL & 6 \\
\hline Hinz et al. (43) & 2012 & 121 & $5(4.1 \%)$ & Thickness, ulceration, CL & 8 \\
\hline Han et al. (44) & 2012 & 271 & $22(8.1 \%)$ & $\begin{array}{l}\text { Thickness, ulceration, MR, TIL, } \\
\text { regression, CL, VGP }\end{array}$ & 7 \\
\hline $\begin{array}{l}\text { Elsaesser et al. } \\
(45)\end{array}$ & 2012 & 212 & $2(0.9 \%)$ & Nil & 7 \\
\hline Yonick et al. (46) & 2011 & 147 & $16(10.9 \%)$ & Nil & 6 \\
\hline Lowe et al. (47) & 2011 & 260 & $9(3.5 \%)$ & Nil & 7 \\
\hline
\end{tabular}


TABLE 1 | Continued

\begin{tabular}{|c|c|c|c|c|c|}
\hline Study & Year & $\begin{array}{l}\text { Total No. of thin melanoma } \\
\text { patients undergoing SLNB }\end{array}$ & $\begin{array}{l}\text { Total No. of thin melanoma patients } \\
\text { with positive SLN (\%) }\end{array}$ & High-risk features reported & $\begin{array}{l}\text { Risk of bias Score } \\
\text { (NOS) (Max=9) }\end{array}$ \\
\hline $\begin{array}{l}\text { Vermeeren et al. } \\
\text { (48) }\end{array}$ & 2010 & 78 & $5(6.4 \%)$ & Thickness, ulceration, CL & 7 \\
\hline $\begin{array}{l}\text { Socrier et al. } \\
\text { (49) }\end{array}$ & 2010 & 68 & $9(13.2 \%)$ & Regression & 6.5 \\
\hline $\begin{array}{l}\text { Santillan et al. } \\
(50)\end{array}$ & 2010 & 72 & $5(6.9 \%)$ & Nil & 7 \\
\hline Mitra et al. (51) & 2010 & 320 & $24(7.5 \%)$ & Nil & 6 \\
\hline Kunte et al. (52) & 2010 & 147 & $11(7.5 \%)$ & Thickness & 7 \\
\hline Ellis et al. (53) & 2010 & 105 & 2 (1.9\%) & Nil & 7 \\
\hline Testori et al. (54) & 2009 & 358 & $4(1.1 \%)$ & Nil & 7 \\
\hline Wright et al. (55) & 2008 & 631 & 31 (4.9\%) & Thickness, ulceration, CL & 6.5 \\
\hline Roulin et al. (56) & 2008 & 51 & 3 (5.9\%) & $\mathrm{CL}$ & 7 \\
\hline Kaur et al. (57) & 2008 & 62 & 2 (3.2\%) & Regression & 7.5 \\
\hline $\begin{array}{l}\text { Starz and Balda } \\
\text { (58) }\end{array}$ & 2007 & 87 & $10(11.5 \%)$ & Nil & 6.5 \\
\hline $\begin{array}{l}\text { Koskivuo et al. } \\
\text { (59) }\end{array}$ & 2007 & 141 & $5(3.5 \%)$ & $\mathrm{Nil}$ & 7 \\
\hline $\begin{array}{l}\text { Vaquerano et al. } \\
(60)\end{array}$ & 2006 & 91 & $6(6.6 \%)$ & $\mathrm{Nil}$ & 7 \\
\hline Ranieri et al. (61) & 2006 & 184 & $12(6.5 \%)$ & $\begin{array}{l}\text { Thickness, ulceration, regression, CL, } \\
\text { VGP }\end{array}$ & 7 \\
\hline $\begin{array}{l}\text { Nowecki et al. } \\
\text { (62) }\end{array}$ & 2006 & 260 & $17(6.5 \%)$ & Nil & 7 \\
\hline $\begin{array}{l}\text { Karakousis et al. } \\
\text { (63) }\end{array}$ & 2006 & 882 & $38(4.3 \%)$ & $\begin{array}{l}\text { Thickness, ulceration, MR, } \\
\text { regression, CL, VGP }\end{array}$ & 8 \\
\hline $\begin{array}{l}\text { Hershko et al. } \\
(64)\end{array}$ & 2006 & 64 & $5(7.8 \%)$ & $\mathrm{CL}$ & 7 \\
\hline $\begin{array}{l}\text { Cascinelli et al. } \\
\text { (65) }\end{array}$ & 2006 & 145 & $6(4.1 \%)$ & Nil & 7 \\
\hline Rex et al. (66) & 2005 & 73 & $3(4.1 \%)$ & Nil & 7 \\
\hline Puleo et al. (67) & 2005 & 409 & $20(4.9 \%)$ & $\mathrm{CL}$ & 7 \\
\hline $\begin{array}{l}\text { Kesmodel et al. } \\
\text { (68) }\end{array}$ & 2005 & 181 & $9(5.0 \%)$ & Thickness, ulceration, MR, CL & 7 \\
\hline $\begin{array}{l}\text { Stitzenberg } \\
\text { et al. (69) }\end{array}$ & 2004 & 146 & $6(4.1 \%)$ & Ulceration, regression, CL & 6 \\
\hline $\begin{array}{l}\text { Borgognoni } \\
\text { et al. (70) }\end{array}$ & 2004 & 114 & $2(1.8 \%)$ & Nil & 7 \\
\hline $\begin{array}{l}\text { Rousseau et al. } \\
(71)\end{array}$ & 2003 & 388 & $4(1.0 \%)$ & Nil & 6 \\
\hline $\begin{array}{l}\text { Oliveira Filho } \\
\text { et al. (72) }\end{array}$ & 2003 & 77 & $6(7.8 \%)$ & Ulceration, regression, CL, VGP & 7 \\
\hline $\begin{array}{l}\text { Jacobs et al. } \\
\text { (73) }\end{array}$ & 2003 & 63 & $2(3.2 \%)$ & $\mathrm{CL}$ & 6 \\
\hline $\begin{array}{l}\text { Bleicher et al. } \\
\text { (74) }\end{array}$ & 2003 & 272 & $8(2.9 \%)$ & Thickness & 6 \\
\hline $\begin{array}{l}\text { Agnese et al. } \\
(75)\end{array}$ & 2003 & 91 & $1(1.1 \%)$ & Nil & 7 \\
\hline $\begin{array}{l}\text { Statius Muller } \\
\text { et al. (76) }\end{array}$ & 2001 & 104 & $7(6.7 \%)$ & Thickness & 7 \\
\hline
\end{tabular}

SLNB, sentinel lymph node biopsy; CL, Clark level; MR, mitotic rate; TIL, tumor-infiltrating lymphocytes; VGP, vertical growth phase; LVI, lymphovascular invasion; PTL, primary tumor location.

the most predictive factor for SLN positivity, while Clark level IV/V did not show a significant correlation with SLN positivity.

A limitation of the previous meta-analysis is the relatively small sample size of included studies. Only one study provided the data on the pathologic features of patients with a sample size larger than 1,000 for analysis. Several large-scale studies were published after 2015 which supplemented the insufficiency of the previous meta-analysis in the adjusted odds ratios analyses. In our study, 6 pieces of literature with a sample size larger than 1,000 were included. The largest one is the study of Conic, et al. published in 2019 with a sample size of 9,186, and it provided data on pathologic features that are available for both unadjusted and adjusted OR analyzing. Thus, we could obtain more accurate predictive values of pathologic and clinical features for SLN positivity. And the $95 \%$ CIs of unadjusted ORs for all features analyzed in our study were narrower than those reported in the previous meta-analysis.

The presence of microsatellites was recognized to have a 3.8fold higher risk and positive rate of $16.6 \%$ for SLN positivity in our study, which means it is the strongest predictor among the 


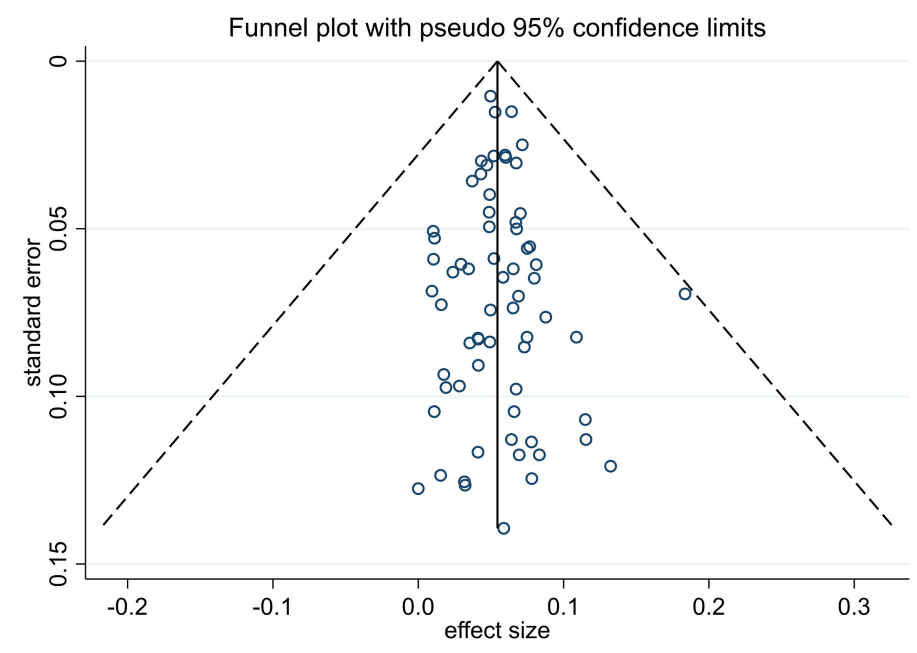

FIGURE 2 | Funnel plot of included studies.

pathologic features we analyzed. Microsatellites are a rarely present pathologic feature associated with poor prognosis and are more likely found in thicker melanoma (78). Four studies in our meta-analysis including 1411 patients with thin melanoma reported data on microsatellites $(18,25,32,41)$. Two of them demonstrated a remarkable increase in SLN positive rate when microsatellites were present, but none of the four studies found it statistically significant because of the infrequence of events.

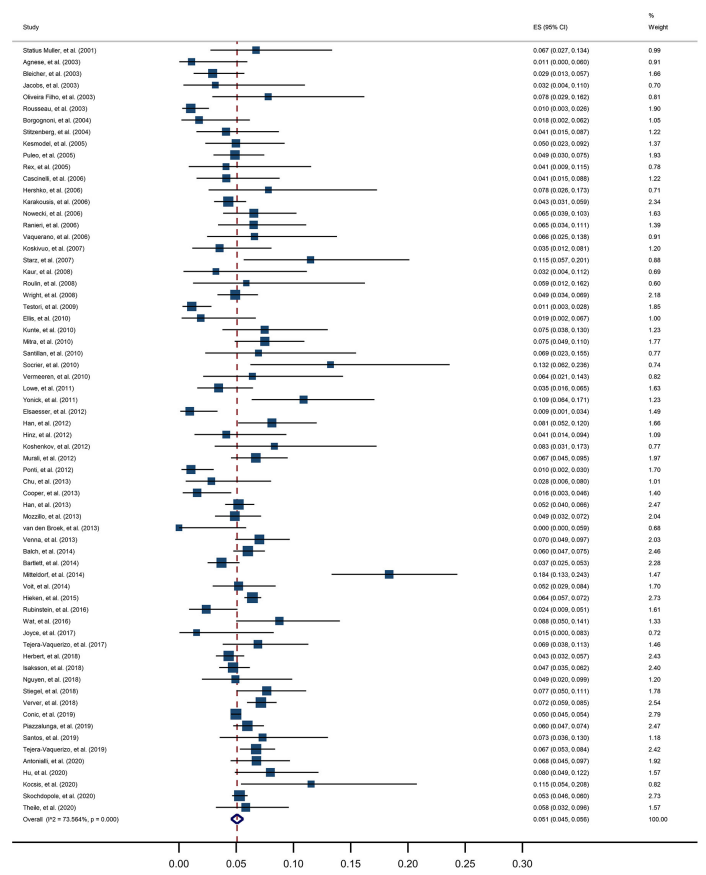

FIGURE 3 | Meta-analysis of sentinel lymph node biopsy positivity in thin melanoma.
Adjusted analysis for microsatellites was not available because relevant researches were too few. And it is the same reason why the adjusted analysis was not done for the vertical growth phase. Regression in primary melanoma has been reported as a protective factor that relates to lower SLN positivity (79) and lower risk of death (80). A host immunologic response to the tumor is considered to play a role in the presence of regression. However, regression did not show significance relativity of SLN positivity in unadjusted analysis nor adjusted analysis in this study.

The pooled positive rate of SLNB in thin melanoma in this study was $5.1 \%$. When patients were confirmed with melanomas of Breslow thickness $\geq 0.8 \mathrm{~mm}$ or mitosis rate $>0 / \mathrm{mm}^{2}$, the pooled positive rate of SLNB would rise to $7.0 \%$ and $7.7 \%$, respectively. Therefore, we suggest that surgeons should consider giving SLNB to such patients. And when a combination of highrisk features is found, the patient should be informed of the even higher rate of SLN positivity.

Our study has some limitations. All studies performed SLNB only in patients with thin melanoma when there was any highrisk feature; therefore, the overall positive rate of SLNB was undoubtedly higher than the true incidence of SLN positivity in all thin melanomas. Significant heterogeneity among the included studies $\left(\mathrm{I}^{2}=73.6 \%, \mathrm{p}<0.001\right)$ was found using a weight estimated random-effects model in the meta-analysis. This probably resulted from several included studies with a higher proportion of positive SLNs. The reporting of identical pathologic features, such as mitosis rate, differed in some of the included studies by defining different cutoff values. This may lead to bias in analyzing its odds ratio. Since this meta-analysis was based on the study level, this variation could also increase the heterogeneity. A patient-level meta-analysis may help to avoid this variation and assess adjusted ORs for more pathologic features. For pathologic features such as microsatellites and the vertical growth phase, more research is needed to clarify their predictive value with larger data sets. Besides the risk factors 
TABLE 2 | Predictive value of high-risk pathologic and clinical features for sentinel lymph node biopsy positivity.

\begin{tabular}{|c|c|c|c|c|c|c|}
\hline Predictor & $\begin{array}{l}\text { No. of } \\
\text { studies }\end{array}$ & $\begin{array}{l}\text { No. of thin melanoma } \\
\text { patients undergoing SLNB }\end{array}$ & $\begin{array}{c}\text { No. of thin melanoma } \\
\text { patients with positive SLN }\end{array}$ & $\begin{array}{c}\text { No. of patients with } \\
\text { positive SLN and } \\
\text { predictor }\end{array}$ & $\begin{array}{l}\text { Unadusted Odds } \\
\text { Ratio }(95 \% \mathrm{Cl})\end{array}$ & $\begin{array}{l}\text { Pooled Positive } \\
\text { Rate }(95 \% \mathrm{Cl})(\%)\end{array}$ \\
\hline $\begin{array}{l}\text { Breslow thickness } \\
<0.8 \mathrm{~mm}\end{array}$ & 23 & 23426 & 1228 & 469 & - & $2.9(2.1-3.7)$ \\
\hline $\begin{array}{l}\text { Breslow thickness } \\
\geq 0.8 \mathrm{~mm}\end{array}$ & 23 & 23426 & 1228 & 759 & $1.61(1.42-1.82)$ & $7.0(6.0-8.0)$ \\
\hline Ulceration & 25 & 17768 & 1108 & 115 & $1.60(1.30-1.97)$ & $4.2(1.8-7.2)$ \\
\hline Regression & 14 & 11065 & 585 & 119 & $0.89(0.72-1.11)$ & $5.2(2.9-8.1)$ \\
\hline Clark Level IV/V & 24 & 15198 & 803 & 421 & $1.68(1.45-1.95)$ & $6.6(5.7-7.6)$ \\
\hline Mitosis Rate $>0 / \mathrm{mm}^{2}$ & 18 & 15002 & 801 & 584 & $2.22(1.88-2.63)$ & $7.7(6.3-9.1)$ \\
\hline $\begin{array}{l}\text { Tumor-infiltrating } \\
\text { Lymphocytes }\end{array}$ & 5 & 1613 & 91 & 51 & $0.69(0.43-1.10)$ & $4.3(2.5-6.5)$ \\
\hline Lymphovascular Invasion & 4 & 1973 & 119 & 6 & $2.39(1.00-5.75)$ & $12.9(0-37.4)$ \\
\hline Microsatellites & 4 & 1411 & 77 & 5 & $3.80(1.38-10.47)$ & $16.6(2.4-36.6)$ \\
\hline Vertical Growth Phase & 5 & 1821 & 112 & 91 & $2.76(1.72-4.43)$ & $8.1(6.3-10.1)$ \\
\hline $\begin{array}{l}\text { Primary Tumor Location } \\
\text { (trunk vs others) }\end{array}$ & 20 & 17345 & 1025 & 432 & $1.10(0.96-1.26)$ & $6.2(4.5-8.2)$ \\
\hline $\begin{array}{l}\text { Primary Tumor Location } \\
\text { (extremities vs others) }\end{array}$ & 20 & 17345 & 1025 & 457 & $0.98(0.86-1.12)$ & $6.4(4.4-8.7)$ \\
\hline
\end{tabular}

TABLE 3 | Pooled adjusted odds ratio of high-risk pathologic features.

\begin{tabular}{|c|c|c|c|c|}
\hline Predictor & No. of studies & No. of thin melanoma patients undergoing SLNB & Adjusted Odds Ratio & $95 \% \mathrm{Cl}$ \\
\hline Ulceration & 8 & 14003 & 2.75 & $1.65-4.60$ \\
\hline Breslow thickness $\geq 0.8 \mathrm{~mm}$ & 10 & 19381 & 1.94 & $1.28-2.95$ \\
\hline Mitosis Rate $>0 / \mathrm{mm}^{2}$ & 8 & 12101 & 1.63 & $1.13-2.36$ \\
\hline Clark Level IVN & 9 & 11924 & 1.24 & $0.84-1.84$ \\
\hline Regression & 7 & 9881 & 1.20 & $0.89-1.63$ \\
\hline
\end{tabular}

analyzed in this study, there are other factors that affect the prognosis of melanoma. Melanin pigmentation plays a role in regulating melanocyte and neighboring cells' behavior (81). It protects melanocytes from UVR but at times accelerates the progression of melanoma and makes melanocytes resistant to different types of therapy (82-84). And as a result, melanin pigmentation shortens overall survival and disease-free survival in metastatic melanoma (82). However, no study has reported the relationship between melanin pigmentation and a positive sentinel lymph node. We look forward to future researches.

\section{CONCLUSION}

The overall positive rate of SLNB in thin melanoma in this study was $5.1 \%$. The strongest predictor for SLN positivity identified was the presence of microsatellites on unadjusted analysis and the presence of ulceration on adjusted analysis. Breslow thickness $\geq 0.8 \mathrm{~mm}$ and mitosis rate $>0 / \mathrm{mm}^{2}$ both predict SLN positivity in adjusted analysis and increase the positive rate to $7.0 \%$ and $7.7 \%$.

\section{REFERENCES}

1. Siegel RL, Miller KD, Jemal A. Cancer Statistics 2020. CA Cancer J Clin (2020) 70(1):7-30. doi: 10.3322/caac.21590

2. Landow SM, Gjelsvik A, Weinstock MA. Mortality Burden and Prognosis of Thin Melanomas Overall and by Subcategory of Thickness, SEER Registry
We suggest patients with thin melanoma with the above high-risk features should be considered for giving an SLNB.

\section{DATA AVAILABILITY STATEMENT}

The original contributions presented in the study are included in the article/supplementary material. Further inquiries can be directed to the corresponding authors.

\section{AUTHOR CONTRIBUTIONS}

$\mathrm{JH}$ and XL contributed to conception and design of the study. ZF and $\mathrm{HH}$ performed articles review and quality assessments. $\mathrm{HH}$ performed the data analyses and wrote the first draft of manuscript. JJ, ZF, and $\mathrm{HH}$ wrote sections of the manuscript. $\mathrm{JJ}, \mathrm{JH}$, and XL helped perform the analysis with constructive discussions. All authors contributed to manuscript revision, read, and approved the submitted version. 
4. Cordeiro E, Gervais MK, Shah PS, Look Hong NJ, Wright FC. Sentinel Lymph Node Biopsy in Thin Cutaneous Melanoma: A Systematic Review and MetaAnalysis. Ann Surg Oncol (2016) 23(13):4178-88. doi: 10.1245/s10434-0165137-z

5. Appleton SE, Fadel Z, Williams JS, Bezuhly M. Vertical Growth Phase as a Prognostic Factor for Sentinel Lymph Node Positivity in Thin Melanomas: A Systematic Review and Meta-Analysis. Plast Reconstr Surg (2018) 141 (6):1529-40. doi: 10.1097/prs.0000000000004395

6. Valsecchi ME, Silbermins D, de Rosa N, Wong SL, Lyman GH. Lymphatic Mapping and Sentinel Lymph Node Biopsy in Patients With Melanoma: A Meta-Analysis. J Clin Oncol (2011) 29(11):1479-87. doi: 10.1200/ jco.2010.33.1884

7. Moody JA, Ali RF, Carbone AC, Singh S, Hardwicke JT. Complications of Sentinel Lymph Node Biopsy for Melanoma - A Systematic Review of the Literature. Eur J Surg Oncol (2017) 43(2):270-7. doi: 10.1016/ j.ejso.2016.06.407

8. Conic RRZ, Ko J, Damiani G, Funchain P, Knackstedt T, Vij A, et al. Predictors of Sentinel Lymph Node Positivity in Thin Melanoma Using the National Cancer Database. J Am Acad Dermatol (2019) 80(2):441-7. doi: 10.1016/j.jaad.2018.08.051

9. Gershenwald JE, Scolyer RA. Melanoma Staging: American Joint Committee on Cancer (AJCC) 8th Edition and Beyond. Ann Surg Oncol (2018) 25 (8):2105-10. doi: 10.1245/s10434-018-6513-7

10. Coit DG, Thompson JA, Albertini MR, Barker C, Carson WE, Contreras C, et al. Cutaneous Melanoma, Version 2.2019, NCCN Clinical Practice Guidelines in Oncology. J Natl Compr Canc Netw (2019) 17(4):367-402. doi: 10.6004/jncen.2019.0018

11. Garbe C, Amaral T, Peris K, Hauschild A, Arenberger P, Bastholt L, et al. European Consensus-Based Interdisciplinary Guideline for Melanoma. Part 2: Treatment - Update 2019. Eur J Cancer (2020) 126:159-77. doi: 10.1016/ j.ejca.2019.11.015

12. Theile H, Moore J, Dunn N, Cossio D, Forristal CE, Green AC, et al. Regional Nodal Metastasis and 5-Year Survival in Patients With Thin Melanoma in Queensland: A Population-Based Study. ANZ J Surg (2020) 90(4):503-7. doi: 10.1111/ans.15804

13. Skochdopole AJ, Kutlu OC, Engelhardt KE, Lancaster WP, Abbott AM, Camp ER. High Mitotic Rate Predicts Sentinel Lymph Node Involvement in Thin Melanomas. J Surg Res (2020) 256:198-205. doi: 10.1016/ j.jss.2020.06.045

14. Kocsis A, Karsko L, Kurgyis Z, Besenyi Z, Pavics L, Dosa-Racz E, et al. Is it Necessary to Perform Sentinel Lymph Node Biopsy in Thin Melanoma? A Retrospective Single Center Analysis. Pathol Oncol Res (2020) 26(3):1861-8. doi: 10.1007/s12253-019-00769-z

15. Hu Y, Briggs A, Gennarelli RL, Bartlett EK, Ariyan CE, Coit DG, et al. Sentinel Lymph Node Biopsy for T1b Melanoma: Balancing Prognostic Value and Cost. Ann Surg Oncol (2020) 27(13):5248-56. doi: 10.1245/s10434-02008558-8

16. Antonialli AZ, Bertolli E, de Macedo MP, Pinto CAL, Calsavara VF, Neto JPD. How Does the Mitotic Index Impact Patients With T1 Melanoma? Comparison Between the 7th and 8th Edition of the American Joint Committee on Cancer Melanoma Staging System. Bras Dermatol (2020) 95 (6):691-5. doi: 10.1016/j.abd.2020.03.020

17. Tejera-Vaquerizo A, Ribero S, Puig S, Boada A, Paradela S, Moreno-Ramírez D, et al. Survival Analysis and Sentinel Lymph Node Status in Thin Cutaneous Melanoma: A Multicenter Observational Study. Cancer Med (2019) 8 (9):4235-44. doi: 10.1002/cam4.2358

18. Santos FMD, Silva FCD, Pedron J, Furian RD, Fortes C, Bonamigo RR. Association Between Tumor-Infiltrating Lymphocytes and Sentinel Lymph Node Positivity in Thin Melanoma. Bras Dermatol (2019) 94(1):47-51. doi: 10.1590/abd1806-4841.20197414

19. Piazzalunga D, Ceresoli M, Allievi N, Ribero S, Quaglino P, Di Lorenzo S, et al. Can Sentinel Node Biopsy be Safely Omitted in Thin Melanoma? Risk Factor Analysis of 1272 Multicenter Prospective Cases. Eur J Surg Oncol (2019) 45 (5):820-4. doi: 10.1016/j.ejso.2018.11.022

20. Verver D, Louwman WJ, Koljenović S, Verhoef C, Grünhagen DJ, van Akkooi ACJ. Improved Stratification of Pt1 Melanoma According to the 8th American Joint Committee on Cancer Staging Edition Criteria: A Dutch PopulationBased Study. Eur J Cancer (2018) 92:100-7. doi: 10.1016/j.ejca.2017.10.031
21. Stiegel E, Xiong D, Ya J, Funchain P, Isakov R, Gastman B, et al. Prognostic Value of Sentinel Lymph Node Biopsy According to Breslow Thickness for Cutaneous Melanoma. J Am Acad Dermatol (2018) 78(5):942-8. doi: 10.1016/ j.jaad.2018.01.030

22. Nguyen B, Karia PS, Hills VM, Besaw RJ, Schmults CD. Impact of National Comprehensive Cancer Network Guidelines on Case Selection and Outcomes for Sentine Lymph Node Biopsy in Thin Melanoma. Dermatol Surg (2018) 44 (4):493-501. doi: 10.1097/DSS.0000000000001369

23. Isaksson K, Nielsen K, Mikiver R, Nieweg OE, Scolyer RA, Thompson JF, et al. Sentinel Lymph Node Biopsy in Patients With Thin Melanomas: Frequency and Predictors of Metastasis Based on Analysis of Two Large International Cohorts. J Surg Oncol (2018) 118(4):599-605. doi: 10.1002/jso.25208

24. Herbert G, Karakousis GC, Bartlett EK, Zaheer S, Graham D, Czerniecki BJ, et al. Transected Thin Melanoma: Implications for Sentinel Lymph Node Staging. J Surg Oncol (2018) 117(4):567-71. doi: 10.1002/jso.24930

25. Tejera-Vaquerizo A, Pérez-Cabello G, Marínez-Leborans L, Gallego E, OliverMartínez V, Martín-Cuevas P, et al. Is Mitotic Rate Still Useful in the Management of Patients With Thin Melanoma? J Eur Acad Dermatol Venereol (2017) 31(12):2025-9. doi: 10.1111/jdv.14485

26. Joyce KM, McInerney NM, Piggott RP, Martin F, Jones DM, Hussey AJ, et al. Analysis of Sentinel Node Positivity in Primary Cutaneous Melanoma: An 8Year Single Institution Experience. Ir J Med Sci (2017) 186(4):847-53. doi: 10.1007/s11845-017-1559-2

27. Wat H, Senthilselvan A, Salopek TG. A Retrospective, Multicenter Analysis of the Predictive Value of Mitotic Rate for Sentinel Lymph Node (SLN) Positivity in Thin Melanomas. J Am Acad Dermatol (2016) 74(1):94-101. doi: 10.1016/ j.jaad.2015.09.014

28. Rubinstein JC, Han G, Jackson L, Bulloch K, Ariyan S, Narayan D, et al. Regression in Thin Melanoma Is Associated With Nodal Recurrence After a Negative Sentinel Node Biopsy. Cancer Med (2016) 5(10):2832-40. doi: $10.1002 / \mathrm{cam} 4.922$

29. Hieken TJ, Grotz TE, Comfere NI, Inselman JW, Habermann EB. The Effect of the AJCC 7th Edition Change in T1 Melanoma Substaging on National Utilization and Outcomes of Sentinel Lymph Node Biopsy for Thin Melanoma. Melanoma Res (2015) 25(2):157-63. doi: 10.1097/ cmr.0000000000000143

30. Voit CA, Gooskens SLM, Siegel P, Schaefer G, Schoengen A, Röwert J, et al. Ultrasound-Guided Fine Needle Aspiration Cytology as an Addendum to Sentinel Lymph Node Biopsy can Perfect the Staging Strategy in Melanoma Patients. Eur J Cancer (2014) 50(13):2280-8. doi: 10.1016/j.ejca.2014.05.027

31. Mitteldorf C, Bertsch HP, Jung K, Thoms KM, Schön MP, Tronnier M, et al. Sentinel Node Biopsy Improves Prognostic Stratification in Patients With Thin (Pt1) Melanomas and an Additional Risk Factor. Ann Surg Oncol (2014) 21(7):2252-8. doi: 10.1245/s10434-014-3641-6

32. Bartlett EK, Gimotty PA, Sinnamon AJ, Wachtel H, Roses RE, Schuchter L, et al. Clark Level Risk Stratifies Patients With Mitogenic Thin Melanomas for Sentinel Lymph Node Biopsy. Ann Surg Oncol (2014) 21(2):643-9. doi: 10.1245/s10434-013-3313-y

33. Balch CM, Thompson JF, Gershenwald JE, Soong SJ, Ding S, McMasters KM, et al. Age as a Predictor of Sentinel Node Metastasis Among Patients With Localized Melanoma: An Inverse Correlation of Melanoma Mortality and Incidence of Sentinel Node Metastasis Among Young and Old Patients. Ann Surg Oncol (2014) 21(4):1075-81. doi: 10.1245/s10434-013-3464-x

34. Venna SS, Thummala S, Nosrati M, Leong SP, Miller JR3rd, Sagebiel RW, et al. Analysis of Sentinel Lymph Node Positivity in Patients With Thin Primary Melanoma. J Am Acad Dermatol (2013) 68(4):560-7. doi: 10.1016/ j.jaad.2012.08.045

35. van den Broek FJ, Sloots PC, de Waard JWD, Roumen RM. Sentinel Lymph Node Biopsy for Cutaneous Melanoma: Results of 10 Years' Experience in Two Regional Training Hospitals in the Netherlands. Int J Clin Oncol (2013) 18(3):428-34. doi: 10.1007/s10147-012-0399-3

36. Mozzillo N, Pennacchioli E, Gandini S, Caracò C, Crispo A, Botti G, et al. Sentinel Node Biopsy in Thin and Thick Melanoma. Ann Surg Oncol (2013) 20(8):2780-6. doi: 10.1245/s10434-012-2826-0

37. Han DL, Zager JS, Shyr Y, Chen HD, Berry LD, Iyengar S, et al. Clinicopathologic Predictors of Sentinel Lymph Node Metastasis in Thin Melanoma. J Clin Oncol (2013) 31(35):4387-93. doi: 10.1200/ JCO.2013.50.1114 
38. Cooper C, Wayne JD, Damstetter EM, Martini M, Gordon J, Guitart J, et al. A 10-Year, Single-Institution Analysis of Clinicopathologic Features and Sentinel Lymph Node Biopsy in Thin Melanomas. J Am Acad Dermatol (2013) 69(5):693-9. doi: 10.1016/j.jaad.2013.07.016

39. Chu VH, Tetzlaff MT, Torres-Cabala CA, Prieto VG, Bassett R, Gershenwald JE, et al. Impact of the 2009 (7th Edition) AJCC Melanoma Staging System in the Classification of Thin Cutaneous Melanomas. BioMed Res Int (2013) 2013:898719. doi: 10.1155/2013/898719

40. Ponti G, Pollio A, Cesinaro AM, Pellacani G, Magnoni C, Seidenari S. Value and Prognostic Significance of Mitotic Rate in a Retrospective Series of Pt1 Cutaneous Malignant Melanoma Patients. Cancer Epidemiol (2012) 36 (3):303-5. doi: 10.1016/j.canep.2011.11.003

41. Murali R, Haydu LE, Quinn MJ, Saw RPM, Shannon K, Spillane AJ, et al. Sentinel Lymph Node Biopsy in Patients With Thin Primary Cutaneous Melanoma. Ann Surg (2012) 255(1):128-33. doi: 10.1097/SLA. 0b013e3182306c72

42. Koshenkov VP, Shulkin D, Bustami R, Chevinsky AH, Whitman ED. Role of Sentinel Lymphadenectomy in Thin Cutaneous Melanomas With Positive Deep Margins on Initial Biopsy. J Surg Oncol (2012) 106(4):363-8. doi: $10.1002 /$ jso.23093

43. Hinz T, Ahmadzadehfar H, Wierzbicki A, Höller T, Wenzel J, Biersack HJ, et al. Prognostic Value of Sentinel Lymph Node Biopsy in 121 Low-Risk Melanomas (Tumour Thickness $<1.00 \mathrm{Mm}$ ) on the Basis of a Long-Term Follow-Up. Eur J Nucl Med Mol Imaging (2012) 39(4):581-8. doi: 10.1007/ s00259-011-2009-4

44. Han D, Yu DH, Zhao XH, Marzban SS, Messina JL, Gonzalez RJ, et al. Sentinel Node Biopsy Is Indicated for Thin Melanomas $>=0.76 \mathrm{Mm}$. Ann Surg Oncol (2012) 19(11):3335-42. doi: 10.1245/s10434-012-2469-1

45. Elsaesser O, Leiter U, Buettner PG, Eigentler TK, Meier F, Weide B, et al. Prognosis of Sentinel Node Staged Patients With Primary Cutaneous Melanoma. PLoS One (2012) 7(1):e29791. doi: 10.1371/journal.pone.0029791

46. Yonick DV, Ballo RM, Kahn E, Dahiya M, Yao K, Godellas C, et al. Predictors of Positive Sentinel Lymph Node in Thin Melanoma. Am J Surg (2011) 201 (3):324-327; discussion 327-328. doi: 10.1016/j.amjsurg.2010.09.011

47. Lowe M, Hill N, Page A, Chen S, Delman KA. The Impact of Shave Biopsy on the Management of Patients With Thin Melanomas. Am Surg (2011) 77 (8):1050-3. doi: 10.1177/000313481107700826

48. Vermeeren L, van der Ent F, Sastrowijoto P, Hulsewé K. Sentinel Lymph Node Biopsy in Patients With Thin Melanoma: Occurrence of Nodal Metastases and its Prognostic Value. Eur J Dermatol (2010) 20(1):30-4. doi: 10.1684/ ejd.2010.0837

49. Socrier Y, Lauwers-Cances V, Lamant L, Garrido I, Lauwers F, Lopez R, et al. Histological Regression in Primary Melanoma: Not a Predictor of Sentinel Lymph Node Metastasis in a Cohort of 397 Patients. Br J Dermatol (2010) 162 (4):830-4. doi: 10.1111/j.1365-2133.2009.09606.x

50. Santillan AA, Messina JL, Marzban SS, Crespo G, Sondak VK, Zager JS. Pathology Review of Thin Melanoma and Melanoma in Situ in a Multidisciplinary Melanoma Clinic: Impact on Treatment Decisions. J Clin Oncol (2010) 28(3):481-6. doi: 10.1200/jco.2009.24.7734

51. Mitra A, Conway C, Walker C, Cook M, Powell B, Lobo S, et al. Melanoma Sentinel Node Biopsy and Prediction Models for Relapse and Overall Survival. Br J Cancer (2010) 103(8):1229-36. doi: 10.1038/ sj.bjc. 6605849

52. Kunte C, Geimer T, Baumert J, Konz B, Volkenandt M, Flaig M, et al. Prognostic Factors Associated With Sentinel Lymph Node Positivity and Effect of Sentinel Status on Survival: An Analysis of 1049 Patients With Cutaneous Melanoma. Melanoma Res (2010) 20(4):330-7. doi: 10.1097/ CMR.0b013e32833ba9ff

53. Ellis MC, Weerasinghe R, Corless CL, Vetto JT. Sentinel Lymph Node Staging of Cutaneous Melanoma: Predictors and Outcomes. Am J Surg (2010) 199 (5):663-8. doi: 10.1016/j.amjsurg.2010.01.019

54. Testori A, De Salvo GL, Montesco MC, Trifirò G, Mocellin S, Landi G, et al. Clinical Considerations on Sentinel Node Biopsy in Melanoma From an Italian Multicentric Study on 1,313 Patients (SOLISM-IMI). Ann Surg Oncol (2009) 16(7):2018-27. doi: 10.1245/s10434-008-0273-8

55. Wright BE, Scheri RP, Ye X, Faries MD, Turner RR, Essner R, et al. Importance of Sentinel Lymph Node Biopsy in Patients With Thin Melanoma. Arch Surg (2008) 143(9):892-9. doi: 10.1001/archsurg.143.9.892
56. Roulin D, Matter M, Bady P, Liénard D, Gugerli O, Boubaker A, et al. Prognostic Value of Sentinel Node Biopsy in 327 Prospective Melanoma Patients From a Single Institution. Eur J Surg Oncol (2008) 34(6):673-9. doi: 10.1016/j.ejso.2007.07.197

57. Kaur C, Thomas RJ, Desai N, Green MA, Lovell D, Powell BWEM, et al. The Correlation of Regression in Primary Melanoma With Sentinel Lymph Node Status. J Clin Pathol (2008) 61(3):297-300. doi: 10.1136/jcp.2007.049411

58. Starz H, Balda BR. Benefit of Sentinel Lymphadenectomy for Patients With Nonulcerated Cutaneous Melanomas in the Breslow Range Between 0.76 and $1 \mathrm{Mm}$ : A Follow-Up Study of 148 Patients. Int J Cancer (2007) 121(3):689-93. doi: $10.1002 /$ ijc. 22707

59. Koskivuo I, Talve L, Vihinen P, Mäki M, Vahlberg T, Suominen E. Sentinel Lymph Node Biopsy in Cutaneous Melanoma: A Case-Control Study. Ann Surg Oncol (2007) 14(12):3566-74. doi: 10.1245/s10434-007-9606-2

60. Vaquerano J, Kraybill WG, Driscoll DL, Cheney R, Kane JM3rd. American Joint Committee on Cancer Clinical Stage as a Selection Criterion for Sentinel Lymph Node Biopsy in Thin Melanoma. Ann Surg Oncol (2006) 13(2):198204. doi: 10.1245/aso.2006.03.092

61. Ranieri JM, Wagner JD, Wenck S, Johnson CS, Coleman JJ3rd. The Prognostic Importance of Sentinel Lymph Node Biopsy in Thin Melanoma. Ann Surg Oncol (2006) 13(7):927-32. doi: 10.1245/aso.2006.04.023

62. Nowecki ZI, Rutkowski P, Nasierowska-Guttmejer A, Ruka W. Survival Analysis and Clinicopathological Factors Associated With False-Negative Sentinel Lymph Node Biopsy Findings in Patients With Cutaneous Melanoma. Ann Surg Oncol (2006) 13(12):1655-63. doi: 10.1245/s10434-006-9066-0

63. Karakousis GC, Gimotty PA, Botbyl JD, Kesmodel SB, Elder DE, Elenitsas R, et al. Predictors of Regional Nodal Disease in Patients With Thin Melanomas. Ann Surg Oncol (2006) 13(4):533-41. doi: 10.1245/aso.2006.05.011

64. Hershko DD, Robb BW, Lowy AM, Ahmad SA, Ramadas GH, Soldano DA, et al. Sentinel Lymph Node Biopsy in Thin Melanoma Patients. J Surg Oncol (2006) 93(4):279-85. doi: 10.1002/jso.20415

65. Cascinelli N, Bombardieri E, Bufalino R, Camerini T, Carbone A, Clemente C, et al. Sentinel and Nonsentinel Node Status in Stage IB and II Melanoma Patients: Two-Step Prognostic Indicators of Survival. J Clin Oncol (2006) 24 (27):4464-71. doi: 10.1200/jco.2006.06.3198

66. Rex J, Paradelo C, Mangas C, Hilari JM, Fernandez-Figueras MT, Fraile M, et al. Single-Institution Experience in the Management of Patients With Clinical Stage I and II Cutaneous Melanoma: Results of Sentinel Lymph Node Biopsy in 240 Cases. Dermatol Surg (2005) 31(11):1385-93. doi: 10.1097/ 00042728-200511000-00002

67. Puleo CA, Messina JL, Riker AI, Glass LF, Nelson C, Cruse CW, et al. Sentinel Node Biopsy for Thin Melanomas: Which Patients Should be Considered? Cancer Control (2005) 12(4):230-5. doi: 10.1177/107327480501200404

68. Kesmodel SB, Karakousis GC, Botbyl JD, Canter RJ, Lewis RT, Wahl PM, et al. Mitotic Rate as a Predictor of Sentinel Lymph Node Positivity in Patients With Thin Melanomas. Ann Surg Oncol (2005) 12(6):449-58. doi: 10.1245/ aso.2005.04.027

69. Stitzenberg KB, Groben PA, Stern SL, Thomas NE, Hensing TA, Sansbury LB, et al. Indications for Lymphatic Mapping and Sentinel Lymphadenectomy in Patients With Thin Melanoma (Breslow Thickness $<$ or $=1.0 \mathrm{Mm}$ ). Ann Surg Oncol (2004) 11(10):900-6. doi: 10.1245/aso.2004.10.002

70. Borgognoni L, Urso C, Vaggelli L, Brandani P, Gerlini G, Reali UM. Sentinel Node Biopsy Procedures With an Analysis of Recurrence Patterns and Prognosis in Melanoma Patients: Technical Advantages Using ComputerAssisted Gamma Probe With Adjustable Collimation. Melanoma Res (2004) 14(4):311-9. doi: 10.1097/01.cmr.0000133968.28172.6e

71. Rousseau DLJr., Ross MI, Johnson MM, Prieto VG, Lee JE, Mansfield PF, et al. Revised American Joint Committee on Cancer Staging Criteria Accurately Predict Sentinel Lymph Node Positivity in Clinically Node-Negative Melanoma Patients. Ann Surg Oncol (2003) 10(5):569-74. doi: 10.1245/ aso.2003.09.016

72. Oliveira Filho RS, Ferreira LM, Biasi LJ, Enokihara MMSS, Paiva GR, Wagner J. Vertical Growth Phase and Positive Sentinel Node in Thin Melanoma. Braz J Med Biol Res (2003) 36(3):347-50. doi: 10.1590/S0100879X2003000300009

73. Jacobs IA, Chang CK, DasGupta TK, Salti GI. Role of Sentinel Lymph Node Biopsy in Patients With Thin $(<1 \mathrm{Mm})$ Primary Melanoma. Ann Surg Oncol (2003) 10(5):558-61. doi: 10.1245/aso.2003.10.025 
74. Bleicher RJ, Essner R, Foshag LJ, Wanek LA, Morton DL. Role of Sentinel Lymphadenectomy in Thin Invasive Cutaneous Melanomas. J Clin Oncol (2003) 21(7):1326-31. doi: 10.1200/jco.2003.06.123

75. Agnese DM, Abdessalam SF, Burak WEJr., Magro CM, Pozderac RV, Walker MJ. Cost-Effectiveness of Sentinel Lymph Node Biopsy in Thin Melanomas. Surgery (2003) 134(4):542-547; discussion 547-548. doi: 10.1016/s0039-6060 (03)00275-7

76. Statius Muller MG, Van Leeuwen PAM, Van Diest PJ, Vuylsteke R.J.C.L.M., Pijpers R, Meijer S. No Indication for Performing Sentinel Node Biopsy in Melanoma Patients With a Breslow Thickness of Less Than 0.9 Mm. Melanoma Res (2001) 11(3):303-7. doi: 10.1097/00008390200106000-00013

77. Wrightson WR, Wong SL, Edwards MJ, Chao C, Reintgen DS, Ross MI, et al. Complications Associated With Sentinel Lymph Node Biopsy for Melanoma. Ann Surg Oncol (2003) 10(6):676-80. doi: 10.1245/aso.2003.10.001

78. Bartlett EK, Gupta M, Datta J, Gimotty PA, Guerry D, Xu XW, et al. Prognosis of Patients With Melanoma and Microsatellitosis Undergoing Sentinel Lymph Node Biopsy. Ann Surg Oncol (2014) 21(3):1016-23. doi: 10.1245/s10434013-3388-5

79. Ribero S, Gualano MR, Osella-Abate S, Scaioli G, Bert F, Sanlorenzo M, et al. Association of Histologic Regression in Primary Melanoma With Sentinel Lymph Node Status: A Systematic Review and Meta-Analysis. JAMA Dermatol (2015) 151(12):1301-7. doi: 10.1001/jamadermatol.2015.2235

80. Gualano MR, Osella-Abate S, Scaioli G, Marra E, Bert F, Faure E, et al. Prognostic Role of Histological Regression in Primary Cutaneous Melanoma: A Systematic Review and Meta-Analysis. Br J Dermatol (2018) 178(2):357-62. doi: $10.1111 /$ bjd.15552

81. Slominski A, Kim TK, Brożyna AA, Janjetovic Z, Brooks DL, Schwab LP, et al. The Role of Melanogenesis in Regulation of Melanoma Behavior:
Melanogenesis Leads to Stimulation of HIF-1 $\alpha$ Expression and HIFDependent Attendant Pathways. Arch Biochem Biophys (2014) 563:79-93. doi: 10.1016/j.abb.2014.06.030

82. Brożyna AA, Jozwicki W, Carlson JA, Slominski AT. Melanogenesis Affects Overall and Disease-Free Survival in Patients With Stage III and IV Melanoma. Hum Pathol (2013) 44(10):2071-4. doi: 10.1016/j.humpath. 2013.02.022

83. Slominski RM, Zmijewski MA, Slominski AT. The Role of Melanin Pigment in Melanoma. Exp Dermatol (2015) 24(4):258-9. doi: 10.1111/exd.12618

84. Brozyna AA, Jozwicki W, Roszkowski K, Filipiak J, Slominski AT. Melanin Content in Melanoma Metastases Affects the Outcome of Radiotherapy. Oncotarget (2016) 7(14):17844-53. doi: 10.18632/oncotarget.7528

Conflict of Interest: The authors declare that the research was conducted in the absence of any commercial or financial relationships that could be construed as a potential conflict of interest.

Publisher's Note: All claims expressed in this article are solely those of the authors and do not necessarily represent those of their affiliated organizations, or those of the publisher, the editors and the reviewers. Any product that may be evaluated in this article, or claim that may be made by its manufacturer, is not guaranteed or endorsed by the publisher.

Copyright (C) 2022 Huang, Fu, Ji, Huang and Long. This is an open-access article distributed under the terms of the Creative Commons Attribution License (CC BY). The use, distribution or reproduction in other forums is permitted, provided the original author(s) and the copyright owner(s) are credited and that the original publication in this journal is cited, in accordance with accepted academic practice. No use, distribution or reproduction is permitted which does not comply with these terms. 